\title{
Harmonising data systems for cash transfer programming in emergencies in Somalia
}

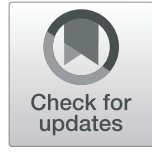

Boniface Owino (D

\begin{abstract}
Quality data and information are fundamental for effective implementation of cash transfer programmes in emergency contexts. Establishing a robust information system can facilitate the equitable and responsive distribution of humanitarian cash-based assistance, while enhancing the effectiveness and efficiency of its delivery. This study presents findings on how various humanitarian agencies are collecting and using registration and identification data in cash transfer programmes in Somalia and identifies opportunities, risks and barriers to establishing an effective integrated data system. The study is based on a systematic review of published and grey literature, as well as on key informant interviews with representatives of humanitarian agencies, donors and government officials in Somalia. The study finds that the collection of registration and identification data is largely based on individual agencies' policies, guidelines and standard operating procedures, resulting in multiple noninteroperable data systems. Progress is being made to harmonise/integrate data systems, including using harmonised registration forms, a common database and data sharing agreements in various consortia; bilateral agreements to share registration platforms; and initiatives by donors and the government to enhance interoperability. Despite this progress, the harmonisation of data systems is still constrained by a number of technical, political, financial and organisational factors, as well as legal, fiduciary, reputational and data protection risks. The study concludes that harmonising data systems presents both long-term opportunities and short-term risks for developing a robust integrated data system for providing cash-based assistance in humanitarian contexts and supporting implementation of social protection programmes.
\end{abstract}

Keywords: Cash transfers, Harmonising data systems, Emergencies, Somalia, Registration and identification

\section{Introduction}

Somalia is experiencing one of the most complex and protracted humanitarian crises in the world. Armed conflicts, weak governance and recurrent climatic shocks perpetuate high levels of humanitarian need and poverty. Since the collapse of the Siad Barre regime in 1991, Somalia has not had a strong central government, leading to more than two decades of lawlessness, violent conflicts, displacement, destruction of property and weak public institutions. Some parts of the country, such as Somaliland and Puntland, have governance frameworks that enjoy relative political stability, security and the support of citizens, but

Correspondence: boniface.owino@devinit.org

Development Initiatives Poverty Research (Africa office), Shelter Afrique Building 4th floor, Mamlaka Road, P.O. Box 102802-00101, Nairobi, Kenya these still lack adequate institutional and financial capacity to build household resilience (Forti 2011). A federal government was formed in 2012 with the support of the United Nations, but political conflict continues to stifle efforts to improve stability and service provision to citizens who rely to a great extent on humanitarian aid to cope with shocks (Mosley 2015).

Humanitarian agencies have used cash transfer programming (CTP) alongside in-kind assistance to save lives and support livelihoods in Somalia for over 10 years (Daniels and Anderson 2018). CTP refers to aid interventions where cash or vouchers (physical or electronic) for goods and services are provided directly to vulnerable or needy households as a means of meeting needs and establishing or rehabilitating livelihoods (Grellety et al. 2017; Mercy Corps 2017; ICRC 2007). The 
suitability of CTP in Somalia is attributed to the monetised economy, the availability of financial services providers and a good network of traders who supply the food and non-food commodities needed by households (Longley et al. 2012).

For many years, Somalia has provided important opportunities for innovation and learning and for developing new approaches to CTP in a conflict-affected and fragile context. As early as 2003/04, CTP was being used, albeit on a small scale, for emergency responses by agencies such as Adeso (formerly Horn Relief). Initial success in CTP in Somalia was attributed in part to the relatively small sizes of the programmes, better security and close monitoring (Hedlund et al. 2013). In 2011, CTP was used at scale to respond to the famine that led to the loss of 258,000 lives (Maxwell et al. 2015). In south and central Somalia, cash-based programmes were the main form of humanitarian assistance, with a total of US $\$ 740$ million delivered to recipients through a mix of instruments, including unconditional cash transfers, conditional cash transfers and business or livelihoods grants between 2011 and 2012 (Hedlund et al. 2013). CTP was also an important aspect of the response to the 20162017 severe drought conditions. For instance, 17\% (US\$214 million) of total humanitarian assistance in Somalia in 2017 had an element of cash (Development Initiatives 2019).

Cash transfer programming entails five distinct processes: the targeting and selection of recipients, registration, enrolment, payment delivery and managing complaints and grievances. Quality data, information and analysis are prerequisites for effective implementation of each of these five stages (Barrett and Kidd 2015). Donors and humanitarian actors are, therefore, increasingly exploring new ways of harmonising/integrating data systems to implement CTPs in an effective, efficient and wellcoordinated manner (European Commission 2019a).

Two approaches can be adopted to establish an integrated data system: developing an integrated beneficiary registry and developing a social registry. An integrated beneficiary registry is essentially a data warehouse that integrates data from the management information systems (MIS) of various programmes. It provides consolidated programme data such as who receives what, from whom and over what duration (Barca 2017). Accordingly, integrated beneficiary registries are appropriate in situations where the key objective of integration is to improve coordination and oversight. Social registries, on the other hand, are "information systems that support outreach, intake, registration and determination of potential eligibility for one or more social programmes" (Leite et al. 2017). They host data for all potential recipients of assistance, whether or not they are considered eligible for those assistance programmes. The main purpose of social registries is to provide a mechanism for targeting by generating information on households ranked according to their well-being, in order to target social assistance to the poor (Chirchir and Farooq 2016). Somalia does not have either of these integrated data systems currently. Accordingly, humanitarian agencies have developed their own data collection and management systems, as well as databases, which have limited interoperability-i.e. the ability of databases, systems or devices to communicate with one another-thereby hindering sharing of data across agencies. This is exacerbated by data protection concerns coupled with legal, ethical and fiduciary risks that prevent sharing of personal data as explained later in this article. These data challenges make it difficult to ensure effective coordination among humanitarian agencies to prevent overlaps and duplication of assistance. Limited sharing of data also constrains caseload management and evaluation of the effectiveness of CTP at the national level to ensure value for money.

The current policy debate on improving the data architecture for CTP in Somalia focuses on how identification and registration of recipients of cash assistance can be done in ways that ensure the most vulnerable are reached, that reduce delays and multiple registration of the same people, that collect data required for programme implementation and that ensure data security. This article contributes to this debate by first shedding light on the current registration and identification practices in CTP in Somalia. It then presents the opportunities for integrating data systems and the challenges that are likely to be faced. Lastly, the article discusses practical steps towards creating an improved data architecture.

While there is a growing body of literature on CTP in humanitarian contexts in Somalia, only a few studies (Goodman and Majid 2017; World Food Programme 2018) have explored the data challenges affecting cash transfer programmes and how they can be addressed. There are knowledge gaps in four key areas: (a) the current operational policies and practices related to the collection and sharing of registration data for CTP in Somalia; (b) the initiatives towards harmonising/integrating data systems, the progress that has been achieved and the challenges encountered; (c) the options for standardising, sharing, storing, monitoring and protecting data in a way that ensures the safety of personal data, increases the efficiency and effectiveness of the response to humanitarian needs and minimises duplication of assistance; and (d) the ethical, fiduciary, reputational and legal risks associated with harmonising/integrating CTP data systems. To fill these knowledge gaps, this study employed a mix of qualitative research techniques. Based on the findings, the study proposes a roadmap for 
establishing an integrated data system for cash transfer programming in Somalia.

\section{Methodology}

The present study is based on primary data and a review of the most current literature on cash transfer programming practices in Somalia. The literature review involved systematic selection and analysis of published and grey literature related to how humanitarian agencies are managing the collection, analysis and sharing of registration and identification data in cash transfer programmes in Somalia, as well as the experience of other fragile and conflict affected countries in harmonising CTP data systems. To measure the strength of the evidence collected, the selected literature was tested using criteria guided by UK's Department for International Development How to Note (Department for International Development 2014) on the strength of evidence and the Overseas Development Institute's guide on how to conduct a rigorous literature review (Hagen-Zanker and Mallett 2013).

The selection of the reviewed literature was guided by the following parameters: (1) conceptual framing-the study acknowledges existing research/literature, constructs a conceptual framework and poses a specific research question or hypotheses; (2) transparency-the study clearly highlights its sources of data, location of the study, research design and limitations; (3) validity and reliability-the study clearly articulates or demonstrates the validity and reliability of its findings; (4) cogency-the study's findings are logical and its conclusions are based on the results; and (5) cultural and gender sensitivity-the study considers context-specific gender and cultural factors that may bias the findings.

Building on the literature review, field consultations were conducted through key informant interviews to gain deeper insights on four issues: (1) the challenges associated with targeting, selecting and registering recipients of cash assistance and what needs to change; (2) the incentives and barriers to harmonising/integrating data systems and sharing recipients' personal data; (3) international best practices/lessons that can be applied in Somalia around harmonisation of data systems; and (4) how Somalia can build an integrated data system for CTP.

To select relevant key informants, stakeholder mapping was carried out, which identified 50 organisations in the humanitarian space in Somalia that were involved in implementing or funding or creating an enabling environment for CTP. Data collection involved documented discussions with a total of 41 key informants. The first strand of data collection involved 29 key informants who were selected through purposive sampling and drawn from non-governmental organisations $(n=$ $20)$, United Nations agencies $(n=4)$, donors $(n=4)$, and the Federal Government of Somalia $(n=1)$. Most of the international agencies that are implementing cash transfer programmes in Somalia and their donors are based in Nairobi. Therefore, much of the data was collected through face-to-face interviews/discussions in Nairobi. Additionally, online discussions were held through Skype with a few informants who were based outside Nairobi.

The second strand of data collection involved discussions with recipients of cash transfers $(n=12)$, to document their experiences during targeting, registration and identification processes in CTP. The issues explored during the discussions included aid recipients' concerns about privacy and data security, how a lack of a national ID system affects access to aid, transparency in beneficiary targeting and selection and how the registration and identification processes can be improved. The discussions were conducted on phone through a Nairobi-based call centre that provides independent third-party monitoring and evaluation of cash transfer programmes in Somalia. This approach was adopted due to insecurity, limited accessibility and time constraints that made it difficult to access the recipients of cash transfers in Somalia. The recipients were selected through random sampling based on beneficiary lists from three different humanitarian agencies operating in Banadir, Hiran and Middle Shabelle regions of the Federal Republic of Somalia. The information obtained through the discussions was triangulated with the literature, including programme monitoring and post-distribution evaluation reports.

In this study, the harmonisation of data systems was conceptualised as a function of political-economy, policy and technical factors that either incentivise or disincentivise various actors-humanitarian agencies, donors and the Federal Government of Somalia-to cooperate and integrate data systems.

Preliminary analysis involved a review of the qualitative data to determine consistency and patterns in the responses and the emerging messages. The initial review also helped to identify information that needed to be clarified and validated through further consultations with stakeholders and triangulated with the literature to generate adequate content to answer the research questions. Next, content analysis method was used to conduct an in-depth analysis of the qualitative data. This involved systematic reduction of the content with special attention to the context it was generated to identify emerging themes and to extract meaningful interpretations of the data. Interview transcripts were reviewed and coding categories were developed based on the data and insights from similar studies. This was an iterative process that involved coding sample text, reviewing coding consistency and revising the coding rules to improve consistency. The coding scheme was then used to categorise the content into various themes for an in-depth 
review. The properties and dimensions of the themes were explored to identify the emerging relationships and to draw inferences and meanings from the data. The information generated from this review was assigned to relevant research objectives and synthesised, resulting in precise and meaningful statements to answer the research questions.

\section{Results}

\section{Targeting and selection of recipients of cash transfers}

The collection of registration and identification data in cash transfer programmes in Somalia relies on policies, guidelines and standard operating procedures developed by individual humanitarian agencies. The United Nations High Commissioner for Refugees and the Cash Learning Partnership have developed operational guidance and a toolkit for multi-purpose cash assistance that provides a set of standards and best practices for implementing cash transfer programmes and can be deployed in emergency contexts (UNHCR et al. 2015). Similarly, the Cash Learning Partnership has developed a toolkit aimed at guiding humanitarian agencies in providing cash assistance in urban settings (Cross and Johnston 2011). The International Committee of the Red Cross's Cash in Emergencies Toolkit provides guidelines for registering recipients, as well as establishing and using databases to manage registration data (ICRC 2007). However, the guidelines do not cover data sharing and protection. The Somalia Food Security Cluster also has guidelines that cover targeting and registration but do not address data protection and sharing. Mercy Corps has developed more elaborate guidelines for CTP that cover data protection, coordination with other agencies and data sharing and management, as well as seeking consent to share data where appropriate. The guidelines also cover the handling of feedback and complaints in cash transfer programmes and the use of alternative identification (ID) documents where a national ID system does not exist (Mercy Corps 2017).

The selection of recipients of cash transfers, particularly in areas that are accessible to aid workers, is based on a two-stage process that includes geographical targeting and community-based targeting. Geographical targeting involves identifying a location with vulnerable households based on Integrated Food Security Phase Classification (IPC) data, with most humanitarian agencies targeting locations with IPC level 3 (crisis), 4 (emergency) and 5 (famine). This is followed by communitybased targeting, which relies on members of the community to select recipients, based on the premise that community members have a better understanding of their own vulnerability than external actors (Mackey and Gol 2018). In Somalia, the targeting and selection of recipients is facilitated by village relief committees (VRCs), internally displaced persons (IDP) camp committees and local authorities including clan elders, chiefs, district commissioners and business people. VRCs are made up of elected or self-appointed members of the community, whereas IDP camp committee members can be elected by IDPs, appointed by 'gatekeepers' or can be selfappointed, depending on the power dynamics of the camp. Gatekeepers are "sophisticated networks of interference: individuals and organisations who position themselves to harness humanitarian assistance flows for their own personal or political advantage" (United Nations Security Council 2012). Thus, the level of representativeness and therefore fairness of VRCs and IDP camp committees in selecting recipients of cash transfers is influenced in part by how their members are appointed as described by a staff member of a humanitarian agency:

We sometimes go to a community and find established VRCs that consist of only one clan or exclude women and people with disabilities. However, due to insecurity and clan tensions, it is not possible to reconstitute the VRCs to ensure accountability and fairness. (Humanitarian agency respondent 10 April 2019)

In practice, the effectiveness of geographical and community-based targeting in Somalia is influenced sometimes strongly-by factors such as elite capture, corruption, favouritism, limited accessibility due to insecurity and clan power dynamics, and this leads to errors of inclusion and exclusion. International and local agencies are often part of these dynamics (Majid et al. 2017). In particular, local authorities, VRCs, gatekeepers and humanitarian agencies are known to collude and to favour certain geographical areas or family and friends, to create 'ghost' recipients of cash assistance to divert aid, and to tax recipients (Majid and Harmer 2016). An interviewed staff of a donor agency, for instance, stated that most of the humanitarian agencies they work with have established guidelines for using community-based targeting, but these are not followed when local authorities threaten to resort to violence if their interests are not considered. In urban areas where cash transfer programmes are concentrated (due to the relative security of such areas and therefore better access), marginalised groups face exclusion because they lack the networks needed to obtain assistance and the fact that they do not belong to the majority clans that control the distribution of aid.

Humanitarian agencies try to address exclusion and inclusion errors during targeting by conducting several rounds of verification through household visits. However, this requires a lot of time, leading to delays in the targeting and registration processes. Verification is impossible to implement where access is limited because of 
insecurity or poor transport infrastructure and is limited by processes of collusion. Most humanitarian agencies have a complaints and feedback mechanism for dealing with concerns raised by recipients during registration and distribution of aid. However, recipients are often not aware of how such mechanisms work. Humanitarian agencies have also invested in internal control systems and external monitoring mechanisms such as third-party monitoring and evaluation to ensure accountability. However, realisation of the full potential of these initiatives is hindered by the incentives to minimise negative monitoring and evaluation feedback (Majid and Menkhaues 2019).

\section{Registration and identification of recipients}

Registration is the process of collecting and formally recording specific information/data about individuals or households. A flawed registration process that leads to exclusion or difficulties in accessing aid can strain the relationships between affected populations, humanitarian agencies and local authorities, which in turn may affect the efficiency and effectiveness of aid distribution. While accurate registration data is important for targeting assistance to the most vulnerable populations, a high degree of accuracy is often difficult to achieve in an emergency due to instability, conflicts and insecurity that limit access to populations, as is the case in Somalia.

Registration data in most cash transfer programmes in Somalia is collected mainly on a demand basis. The data collected depends on the context and the programme objectives, which vary across agencies. Typically, the data collected includes biodata such as name, age, gender, contact details, biometrics, household size and location. Also, data is collected for use in eligibility assessment based on indicators such as asset ownership, nutritional status, chronic illness and disability status. Humanitarian agencies have adopted different digital registration platforms that include both proprietary and open source data collection platforms to ensure efficiency, accuracy of data capture and data protection through measures such as encryption (Table 1). However, cost considerations coupled with concerns about data ownership, access, privacy and protection hinder the use of existing digital registration platforms. This is exacerbated by a lack of strong government regulation to address data privacy and protection concerns. Some humanitarian agencies still use manual registration processes that are time-consuming, labour-intensive and prone to errors. The interviewed recipients of cash aid believed that digital registration is more time-efficient than paper-based registration, but does not necessarily prevent the errors that often cause delays in aid distribution. Eliminating errors at the registration stage is central to harmonising data systems since errors can easily be propagated in an integrated data system where data is shared to inform aid distribution decisions across agencies.

In Somalia, data is collected every time a new cash transfer programme is launched rather than using data from previous programmes, which in most cases is either discarded or handed over to the funding partner. This is attributed to a lack of consent to transfer data from one programme to another, the need to collect new data when humanitarian agencies move to new locations, inclusion and exclusion errors in existing datasets and the fact that data is not updated regularly. Table 2 summarises similarities and differences in registration processes. Aid recipients stated that they face difficulties in participating in multiple registration exercises, especially if they have to travel to far-away registration centres which exposes them to security risks. This contributes to exclusion of women who are exposed to sexual and physical assaults while traveling to registration centres and older people and people with disabilities who have mobility challenges.

Identification refers to the process of establishing, determining or recognising the identity (unique characteristics and features) of an individual. Identity verification, therefore, involves "confirmation and establishing of a link between a claimed identity and the actual living person presenting the evidence" (World Bank 2018a). Somalia lacks a national foundational identification system and depends on multiple non-interoperable ID systems with coverage limited to specific regions or social assistance programmes. A foundational ID is an identification system established principally to provide legal identification and credentials to the entire population to support public administration and access to services provided by public, private and non-governmental organisations (World Bank 2018b). Table 3 summarises the identification systems used in cash transfer programmes in Somalia, along with their strengths and weaknesses.

\section{Biometric identification in Somalia}

In the absence of a foundational ID system in Somalia, there are debates as to whether a biometric identification system can be established. A biometric is essentially a representation of a characteristic of an individual such as fingerprints, which can be processed into a biometric profile for identification or verification (Clark 2017). Most humanitarian agencies that have acquired biometric technology in Somalia are using it mainly for verification rather than for identification purposes. Identification entails a one-to-many $(1: \mathrm{N})$ matching process in which an individual's biometric profile is compared against the biometric profiles of all persons who are using the biometric identification system. 1:N matching is relevant in situations where the key objective of using biometrics is to identify 
Table 1 Examples of digital registration platforms used by some aid providers in Somalia

\begin{tabular}{|c|c|c|}
\hline Name & Owner/developer & Users \\
\hline System for Cash Operations & World Food Programme & $\begin{array}{l}\text { World Food Programme, Food and Agriculture Organization, Danish Refugee } \\
\text { Council, United Nations Children's Fund and World Vision }\end{array}$ \\
\hline Last Mile Mobile Solutions & World Vision & World Vision \\
\hline $\begin{array}{l}\text { Biometric Automated } \\
\text { Fingerprint Identification } \\
\text { System }\end{array}$ & Cooperazione Internazionale & Cooperazione Internazionale \\
\hline $\begin{array}{l}\text { Profile Global Registration } \\
\text { System }\end{array}$ & $\begin{array}{l}\text { United Nations High } \\
\text { Commissioner for Refugees }\end{array}$ & United Nations High Commissioner for Refugees \\
\hline Cash and Asset Transfer & Catholic Relief Services & Catholic Relief Services \\
\hline Displacement Tracking Matrix & $\begin{array}{l}\text { International Organization for } \\
\text { Migration }\end{array}$ & International Organization for Migration \\
\hline Open Data Kit & $\begin{array}{l}\text { Open Data Kit—developed by } \\
\text { University of Washington }\end{array}$ & $\begin{array}{l}\text { Agency for Technical Cooperation and Development, Social-Life and Agricultural } \\
\text { Development Organisation and Adeso }\end{array}$ \\
\hline Ona & Ona Kenya Ltd & $\begin{array}{l}\text { Agency for Technical Cooperation and Development, Concern Worldwide, } \\
\text { Cooperazione Internazionale, Danish Refugee Council, Save the Children, } \\
\text { Norwegian Refugee Council, International Rescue Committee, Cooperazion e } \\
\text { Sviluppo Onlus and Food and Agriculture Organization }\end{array}$ \\
\hline KoBo & $\begin{array}{l}\text { KoBoToolbox-Harvard } \\
\text { Humanitarian Initiative }\end{array}$ & $\begin{array}{l}\text { Save the Children, United Nations High Commissioner for Refugees and } \\
\text { International Organization for Migration }\end{array}$ \\
\hline sQuid & Smart Transactions Ltd & Save the Children \\
\hline $\begin{array}{l}\text { Biometrics Technology System } \\
\text { (BITS) }\end{array}$ & $\begin{array}{l}\text { Food and Agriculture } \\
\text { Organization }\end{array}$ & Food and Agriculture Organization \\
\hline $\begin{array}{l}\text { Biometric Money Application } \\
\text { (BiMo) }\end{array}$ & $\begin{array}{l}\text { Food and Agriculture } \\
\text { Organization }\end{array}$ & Food and Agriculture Organization \\
\hline CommCare & Dimagi & International Rescue Committee \\
\hline
\end{tabular}

duplicate registration (deduplication) of individuals in cash transfer programmes. Verification, on the other hand, is a 1:1 matching exercise that involves comparing a newly collected biometric profile with a single profile stored in a programme database (Clark 2017).

In Somalia, biometric identification is hindered by a lack of standardisation in the way that biometric data is collected and saved. There is also no consistency in the type of biometric data captured and no agreement on the data that can be exchanged to ensure biometric interoperability. The International Organization for Standardization and the International Electrotechnical Commission have developed the ISO/IEC 19794-1:2011 standard to guide the standardisation of biometric data, and this could be adopted to establish a biometric ID system in Somalia (International Organization for Standardization 2017).

Table 2 A summary of similarities and differences in registration processes

\begin{tabular}{ll}
\hline & Similarities \\
\hline $\begin{array}{l}\text { Frequency } \\
\text { of }\end{array}$ & $\begin{array}{l}\text { Registration is done afresh every time a new programme is } \\
\text { launched instead of using existing data. }\end{array}$ \\
registration & \\
$\begin{array}{ll}\text { Registration } \\
\text { modalities }\end{array}$ & $\begin{array}{l}\text { Registration is often done through interviews with potential } \\
\text { recipients of assistance. }\end{array}$
\end{tabular}

Level of Data is collected at household level. The majority of humanitarian data agencies record only the details of the principal recipient and/or collection their next of kin.

\section{Differences}

Registration cycles vary between every three and every 12 months.

Some humanitarian agencies such as the Somalia Cash Consortium partners, register aid recipients through household visits, while others carry out registration in centralised locations. Different digital registration platforms, as well as manual systems are used for registration.

While most humanitarian agencies register only actual recipients approved by the community during targeting, the World Food Programme and United Nations High Commissioner for Refugees, which are major providers of cash assistance, register both potential and actual recipients.

Updating Data is updated if there is top-up assistance or the duration of the data programme is extended.
The frequency of updating data varies from every month to every year. 
Table 3 The main identification systems used in cash transfer programmes in Somalia

\begin{tabular}{|c|c|c|}
\hline Identification system & Strengths & Weaknesses \\
\hline $\begin{array}{l}\text { Functional ID: an ID system established to } \\
\text { address a particular need such as delivering } \\
\text { cash assistance }\end{array}$ & $\begin{array}{l}\text { Enables humanitarian agencies to uniquely } \\
\text { identify the recipients of their cash } \\
\text { assistance. }\end{array}$ & $\begin{array}{l}\text { Cannot facilitate deduplication across agencies since every } \\
\text { humanitarian agency issues its own identification numbers. } \\
\text { Leads to use of multiple ID cards, which is inconvenient } \\
\text { for recipients of assistance. }\end{array}$ \\
\hline $\begin{array}{l}\text { Phone numbers registered to receive cash } \\
\text { transfers }\end{array}$ & $\begin{array}{l}\text { Phone numbers are unique-no identical } \\
\text { numbers. } \\
\text { Phone numbers are linked to recipients' } \\
\text { biodata during subscriber identity module } \\
\text { (SIM) registration. } \\
\text { Phone numbers have a personal } \\
\text { identification number (PIN) for security. }\end{array}$ & $\begin{array}{l}\text { Recipients can have multiple phone numbers, thereby } \\
\text { creating fraud/duplication risks. } \\
\text { Requires regular updating since recipients change phone } \\
\text { numbers. } \\
\text { Some recipients share phone numbers. In such situations, } \\
\text { the numbers are no longer unique identifiers. } \\
\text { Some recipients sell or lease their SIM cards for immediate } \\
\text { cash needs, thereby defeating the purpose of the cash } \\
\text { transfer programmes. }\end{array}$ \\
\hline Biometric technology & $\begin{array}{l}\text { Provides a reliable verification and } \\
\text { identification system for CTP by reducing } \\
\text { duplication risks. }\end{array}$ & $\begin{array}{l}\text { High cost of acquiring the necessary software and } \\
\text { hardware. } \\
\text { Associated with data privacy and protection risks that } \\
\text { must be addressed (see next section). } \\
\text { Requires adoption of a common standard for collecting } \\
\text { and saving biometric data (not yet adopted in Somalia) to } \\
\text { ensure interoperability. }\end{array}$ \\
\hline
\end{tabular}

The process of recording biometrics is subject to error, and the probabilistic matching technique used in biometric identification and verification is subject to statistical variance (United Nations Office of CounterTerrorism 2018). This means that the success of biometric identification depends on the design of the technology, the level of accuracy of data capture and how well the matching parameters are set. However, accuracy can be improved significantly by using more than one biometric technique such as using fingerprints alongside iris or facial scans (Clark 2017). For instance, the Food and Agriculture Organization in Somalia is transitioning from recording two to 10 fingerprints for each person, which will be used alongside a facial recognition system to improve accuracy.

Rolling out a biometric identification system that can be used at scale involves significant upfront investment in the necessary hardware and software. The identification process relies on a complex algorithm that is often provided by vendors as proprietary software, which can be expensive (Chirchir 2017). This means that a clear funding framework should be developed to build and operate a biometric identification system sustainably.

The use of biometrics is also facing resistance due to concerns about personal data protection and identity theft. A database of biometrics can be a target of attack by hackers and scammers or militias such as Al-Shabaab in Somalia. While this is not unique to biometric identification systems, the concern is that, once compromised, a biometric identifier cannot be reissued like a password can. Criminals can also exploit other identifying information linked to stolen biometric data, thereby exacerbating the risk of abuse of personal data. Nonetheless, technologies such as biometric encryption can help to mitigate these data protection and identity theft risks (Gellman 2013). Additionally, enacting effective laws and policies to protect biometric data and encouraging humanitarian agencies to process biometric data in a manner that does not violate the right to privacy is important.

Biometric identification may also lead to exclusion of some people from access to cash transfers in Somalia. For instance, amputees or manual labourers with worn or scarred fingers may not be registered or verified successfully through fingerprint scans and diseases or conditions such as cataracts may affect the quality of verification and identification based on iris scans (Clark 2017). Thus, humanitarian agencies must establish an alternative identification system for those affected to ensure equitable access to aid.

Overall, biometric identification can be used in Somalia, but it is associated with technical, cost and data protection challenges that must be addressed at the outset. There should also be plans and a strategy to transfer biometric data to the government in future, once adequate capacity and data protection measures have been established to support the development of national ID systems. Essentially, it is a waste of resources if multiple actors collect biometrics that cannot be used by the Federal Government of Somalia in the long term.

\section{Initiatives towards harmonising data systems}

This study identified four broad categories of harmonisation initiatives aimed at enhancing interoperability and sharing data among humanitarian agencies that are implementing cash transfer programmes. The first involves collaboration within consortia of humanitarian agencies that have adopted common approaches to implement their cash transfer programmes. These include 
(1) the Somalia Cash Consortium, which includes the Agency for Technical Cooperation and Development, Concern Worldwide, Cooperazione Internazionale, the Danish Refugee Council, Save the Children and the Norwegian Refugee Council; (2) the Somalia Resilience Action Consortium, which includes Agency for Technical Cooperation and Development, the Social-Life and Agricultural Development Organization and Adeso; and (3) the Building Resilient Communities in Somalia Consortium, which consists of Cooperazione e Sviluppo, Concern Worldwide, Norwegian Refugee Council, the International Rescue Committee and Save the Children. Harmonisation efforts within these consortia entail using a harmonised registration form, a common database and data sharing agreements. However, a key limitation in these initiatives is that sharing data is limited to specific joint programmes funded by a common donor.

The second category involves bilateral cooperation among humanitarian agencies to use a common registration platform to collect and/or share data. These include the collaboration between World Food Programme (WFP) and its partners such as the Danish Refugee Council and World Vision to use World Food Programme's System for Cash Operations (SCOPE) for registration in a joint programme. A similar arrangement has been used by Food and Agriculture Organization, World Food Programme and the United Nations Children's Fund to register recipients through SCOPE. These arrangements are driven mainly by contract agreements that require agencies to use a particular platform. So, for instance, WFP requires its partners to use SCOPE to ensure consistent reporting across its programmes and to maintain control over recipients' data. World Food Programme's partners participate mainly in data collection using SCOPE, but have limited control or access to the data after registration since the datasets are managed by WFP. United Nations High Commissioner for Refugees and WFP have a data sharing agreement and have established interoperability between their registration platforms-Profile Global Registration System and SCOPE, respectively. The challenges that hinder sharing of data among humanitarian agencies that are using a common platform include the fear that data might be misused if it is not adequately protected and the bureaucratic decision-making processes that slow approval of the transfer of data from one agency to another.

The third category includes initiatives by a group of donors led by the Directorate-General for European Civil Protection and Humanitarian Aid Operations who are working to transform current cash transfer programmes into a long-term social protection programme in Somalia. A Donor Working Group consisting of humanitarian and development donors was established in 2018 to take forward this initiative (European Union 2019a). A Technical Assistance Facility was established in early 2019 to work on 12 deliverables that included exploring options for developing an integrated beneficiary registry for Somalia and addressing capacity gaps in the government. This initiative, if fully implemented, could lead to a harmonised data system by promoting interoperability between existing databases. However, the initiative is still at a very early stage, which limits the extent to which its potential to contribute to a harmonised data system can be analysed.

The fourth category encompasses government-led initiatives, such as the planned development of a digital ID system with support from Pakistan's National Database and Registration Authority. This system is expected to facilitate data sharing by providing a reliable identification mechanism. However, its development faces significant challenges, including insecurity caused by $\mathrm{Al}$ Shabaab's opposition to the development of ID systems, a general lack of trust in ID systems, difficulties in verifying identities because of the limited availability of breeder documents such as birth certificates and difficulties in reaching populations due to insecurity and poor infrastructure (World Bank 2016). The Somali government is also working with the World Bank to establish a national unified registry-a form of social registry. This initiative is still at a preparatory stage and the government faces significant capacity challenges, including inadequate human and financial resources and technological constraints, which need to be addressed.

Overall, ongoing harmonisation initiatives provide important opportunities for improving interoperability and sharing data. Moreover, harmonisation efforts underpinned by a long-term objective such as developing a social protection programme, which is being spearheaded by the Donor Working Group, are critical for transitioning from relief to long-term development outcomes. However, most of the current harmonisation initiatives are limited to specific programmes being implemented by consortia and poorly coordinated. There is a risk that humanitarian agencies will revert to working in silos at the end of the existing grant contracts that bind them to work together using common approaches.

\section{Incentives and challenges associated with harmonising data systems}

There are a number of incentives for humanitarian agencies and donors to develop an integrated data system for CTP in Somalia. To begin with, humanitarian agencies can benefit from cost savings and efficiency in distribution of aid. Interoperability and sharing data can support establishment of joint processes such as a common payment platform to reduce operating costs. Such collaborative efforts can strengthen humanitarian agencies' bargaining power, thereby allowing them to negotiate 
for better terms or lower fees with financial services providers (European Commission 2019a). Integrating data systems can also enable humanitarian agencies to prevent duplication and overlaps in aid distribution through sharing data. Accordingly, humanitarian agencies can improve the impact of their programmes by reaching more households with limited resources. Additionally, humanitarian agencies can benefit from improved caseload planning by sharing data on key aspects of CTP such as who has been registered, the type of cash transfers they have received, the agency providing the assistance and the duration of the assistance provided to determine the gaps in meeting existing needs.

The incentives for donors include the fact that integrating data systems can contribute to efforts to enhance aid effectiveness by facilitating access to and use of quality data among their partners (humanitarian agencies) to support eligibility assessments, distribution of aid, coordination of response and monitoring programme outcomes to ensure value for money. Integration of data systems can also enhance transparency and accountability to donors by enabling the sharing, analysis and comparison of programme data across humanitarian agencies. Importantly, supporting integration of data systems provides donors with an opportunity to contribute to building an effective government-led data system to support future national social protection programmes to improve household resilience. This will allow donors to reduce investments in relief response as the government takes over the provision of social support in the long term.

Despite the benefits, a number of political economy factors slow harmonisation of CTP data systems in Somalia. To begin with, the politics of ownership and control over access to data prevents collaborative efforts towards harmonisation. Since CTP implementation in Somalia is determined to a great extent by access, controlling ownership and access to registration data is seen as a competitive advantage, as donors prefer to work with agencies with large databases on the premise that such agencies can reach many needy households. Furthermore, fear of the potential disruptions that harmonisation could cause to the current operations of humanitarian agencies leads to resistance. For instance, consolidating registration processes and contracting a single agency to collect registration data to be used by all agencies leads to resistance on the ground that it is likely to shrink the budgets of humanitarian agencies and undermine the investments they have made in establishing data collection and management systems. Major providers of cash assistance have already invested in different MIS/platforms that are customised to their own needs, and which they are not willing to abandon. Therefore, it is important to encourage humanitarian agencies to establish interfaces that allow their MIS/ platforms to communicate with each other, rather than promoting the adoption of a single platform. Donors also lack a common stance on harmonising data systems, leading to poor coordination of harmonisation initiatives. However, the DWG is expected to facilitate discussions among donors to adopt a collaborative approach and to work with all stakeholders to harmonise data systems.

Harmonising data systems is also constrained by technical factors. A key technical challenge is the fact that there is no common unique ID system used by all humanitarian agencies. While a foundational ID system is not a must for integration to be implemented, there must be a mechanism (unique identifier) for matching and linking datasets across databases to ensure interoperability and sharing of data. Another technical challenge is limited standardisation of data fields, which prevents interoperability. For instance, names are spelt differently depending on whether they are recorded in English or Somali, there is no consistency in the way that biometric data is collected and saved, and the definition and measurement of data variables are different across agencies. In addition, humanitarian agencies have limited trust in the quality of data collected by their peers:

We know our organisation has capability to produce quality data, but we cannot trust every agency to produce quality data for use by everyone. This prevents sharing of data as humanitarian agencies focus on collecting their own datasets to avoid errors that might be found in data obtained from external sources. ( $\mathrm{Hu}$ manitarian agency respondent, 17 April 2019)

The extent to which various agencies can participate in harmonising data systems is also limited by their varied technical maturity. While World Food Programme, United Nations High Commissioner for Refugees and World Vision have already developed mature systems that have been tried and tested in different settings or countries, many humanitarian agencies are still trialling both in-house and third-party commercial solutions and some are still using simple Excel-based systems for registration and data management.

Harmonising data systems is also constrained by organisational, ethical and legal factors. Many humanitarian agencies in Somalia lack the consent to share data with third parties. Ethically, personal data cannot be shared with third parties without adequate consent (United Nations Development Group 2017). As an interviewed staff of a humanitarian agency explained in the following extract, obtaining adequate consent should be prioritised to enhance data sharing:

We cannot share the data we have because we lack the consent to do so. In future, our agency and 
other humanitarian agencies should consider obtaining consent to share data at least for duplication checks. (Humanitarian agency respondent, 23 April 2019)

Somalia lacks a national legal framework for data protection, which has contributed in part to the development of several different organisation-level data protection protocols and policies that vary from agency to agency. This has led to differences in understanding of what should be shared, how it should be shared and how the shared data should be used or protected. Accordingly, developing data sharing agreements that conform to the different organisation-level policies remains a significant challenge.

Harmonising data systems also comes with significant risks. There are data privacy and protection risks in an integrated data system that can arise due to unauthorised sharing of data, covert surveillance and hacking or scamming of databases (Carmona 2018). In Somalia, unauthorised sharing of data can put at risk the security of recipients of cash assistance because of the ongoing conflicts in the country. Specifically, recipients can be targeted for violence or harassment because of their political, ethnic, clan or religious background or because they have received aid if their data leaks to militias such as Al-Shabaab. Discussions with aid recipients indicated that most of them have limited knowledge on data privacy and protection risks associated with providing their personal data to humanitarian agencies. Of concern is the fact that, even where recipients are aware of data protection risks, they are not likely to withhold their personal data or question how the data will be protected due to the fear of being excluded from aid.

Integrating data systems also has legal risks in so far as breaching data protection regulations can lead to prosecution and financial penalties (European Commission 2019b). Additionally, misuse of personal data has negative implications for organisational reputation (reputational risks) that can adversely affect access to funding. Finally, there are fiduciary risks that include aid diversion, which can occur if targeting and registration processes are manipulated to include people who do not meet eligibility criteria as recipients. Such inclusion errors can be propagated in an integrated data system, leading to further diversion of aid. While there is consensus among humanitarian agencies that preventing duplication and overlaps in providing cash transfers is a priority reform area that should be addressed urgently, there is limited political will to share data widely and to engage in harmonisation of data systems due to the challenges and risks discussed in the foregoing section. The majority of humanitarian agencies prefer to operate their own databases and share only minimum agreed data variables for planning, deduplication and coordination to minimise risks.

\section{Opportunities for harmonising data systems}

There are important building blocks that provide vital opportunities for harmonising CTP data systems in Somalia. To begin with, humanitarian agencies are already collecting some common data variables that can be standardised across the board for sharing. These include name, age, gender, contact details (usually phone number) household size and location. As a next step, additional data variables can be identified and standardised for sharing. Additionally, the standardised registration forms being used in various consortia can be harmonised further to facilitate integration of data systems. This presents an important opportunity to establish interoperability between the databases of various consortia to scale up sharing of data.

In Somalia, key coordination and leadership structures have been established in the CTP space. These include the Cash Working Group, the Food Security Cluster, the Donor Working Group and the Technical Assistance Facility. Harmonising data systems is aligned to the Donor Working Group's mandate of leading the development of a social protection programme for Somalia and the Technical Assistance Facility's terms of reference, which include exploring ways of creating interoperable databases. As key coordination structures in the CTP space, the Cash Working Group and the Food Security Cluster can provide a forum for discussion and sharing best practices on harmonising data systems. Finally, various open source mobile data collection platforms such as the Open Data Kit and KoBoToolbox provide affordable options for humanitarian agencies that are currently using manual systems to transition to digital platforms, which in turn will enable them to share data more easily with their peers who have already adopted digital platforms. Adopting these open source solutions is cheaper than building bespoke systems. For instance, KoBoToolbox can be accessed and used for free.

\section{Lessons from other fragile and conflict affected states}

A number of important lessons can be drawn from Mali and Palestine in developing data systems to support cash transfer programmes. First, Mali's experience shows that a multi-stakeholder approach is key to effective integration of data systems as it enhances ownership and access to resources. Mali's unified social registry, the Registre Social Unifié (RSU), was developed through a multistakeholder approach that brought together the government, donors, United Nations agencies, and international non-governmental organizations (INGOs). For instance, the Directorate-General for European Civil Protection and Humanitarian Aid Office (DG-ECHO) 
partnered with a consortium of six INGOs to implement two cash transfer programmes-the Common Framework for Seasonal Social Safety Nets or Cadre Commun sur les Filets Sociaux (CCFS) and the Common Framework for Seasonal Social Transfers or Cadre Commun Transferts Sociaux (CCTS) in the period 2014 to 2016 (European Commission 2019c). The six INGOs-Danish Refugee Council, Action contre la Faim, Oxfam, Solidarités International, Humanity and Inclusion (formerly Handicap International) and International Rescue Committee-aligned their programmes (CCFS and CCTS) to Jigisemejiri's-a government-led safety net programme to ensure data sharing. The INGOs also donated their database to the government as part of the initial data that was included in the registry (O'Brien et al. 2018). The World Bank provided part of the funding and capacity building to the government. Additionally, United Nations Children's Fund contributed to capacity development in the government to support operationalisation of the registry. The government provided leadership and strong political will, which was demonstrated by the inclusion of a unified registry as a key output of the national social protection strategy.

Second, integrating data systems should be driven by a clear long-term objective to ensure success. In Mali, the overarching objective was to institutionalise social protection interventions. Accordingly, donors such as DG$\mathrm{ECHO}$ and non-governmental organisations such as the CCFS and CCTS partners, which were interested in contributing to this objective harmonised targeting and registration processes among themselves and with the government-led CTP-Jigisemejiri-to ensure data sharing (O'Brien et al. 2018). Having such a clear objective could enhance harmonisation outcomes in Somalia by promoting collaborative and well-coordinated efforts.

Third, the process of integrating data systems can start with a few agencies, such as the six CCTS agencies, that are interested in collaborating among themselves and with the government. Such initiatives can be scaled up over time to establish an integrated data system. This could be a more practical option in Somalia where building consensus on all aspects of integrating data systems is slowed by challenges such as data protection concerns and direct competition for funding among humanitarian agencies.

Fourth, establishing a robust MIS should be prioritised to facilitate access to and use of data in an integrated data system. Palestine's unified registry, for instance, is supported by a MIS that connects the Ministry of Social Development which implements the Palestinian National Cash Transfer Programme to all its 17 district offices, thereby allowing users of the registry to access data in real-time (World Bank 2017). This ensures efficient access to data for planning/decision-making which can be an incentive to humanitarian agencies in Somalia to support development of an integrate data system.

Finally, a mechanism for regular re-verification of household vulnerability is required to enhance data quality. In Palestine, for instance, the data is updated regularly by a network of social workers to enhance its suitability for distribution of cash assistance. In Somalia, updating data regularly is important to reduce the inclusion and exclusion errors that arise during targeting and registration and which prevent sharing existing datasets.

\section{Discussion}

\section{Roadmap for establishing an integrated data system}

Given the opportunities, risks and challenges, the extent to which data systems in Somalia can be harmonised is limited in the short term. However, better harmonisation can be achieved in the medium and long terms as stakeholders address the risks and challenges. The process of establishing and operating an integrated data system should be aligned fully to humanitarian principles to ensure successful implementation of cash transfer programmes. In Somalia, humanitarian principles have historically been compromised due to the political economy of aid in the country. The operations of humanitarian agencies are influenced by local power dynamics which, contrary to the principles of neutrality, independence and impartiality, perpetuate structural inequalities (Hammond and Vaugham-Lee 2012). For instance, although negotiating with and paying militias to gain access is key to reaching vulnerable populations, such approaches are seen by critics as legitimising or supporting outlawed groups. Humanitarian agencies must avoid causing harm to recipients of assistance through, for instance, data privacy or protection breaches that may occur during or after integrating data systems. From the outset, an oversight mechanism should be established to ensure that data is collected, shared and used in a manner that does not favour a particular demographic group, political entity or certain parties to a conflict. This requires humanitarian agencies to promote professionalism and empower their staff to resist the pressure to manipulate targeting and registration processes, which in turn will enhance the integrity of the data collected and shared.

In Somalia, a key objective of humanitarian agencies and donors in the short term is to establish a data system that can facilitate deduplication, coordination and caseload planning. Nonetheless, there is lack of a reliable identification system, and humanitarian agencies are willing to share only a few data variables due to the risks discussed earlier. In the long term, there is agreement among various actors that a registry that can support the implementation of social protection programmes should be developed. However, the ability of the government of 
Somalia to establish and manage an integrated beneficiary registry or a social registry in the short term is limited by significant technical, financial and political challenges, as well as a lack of supportive legal and institutional frameworks (Federal Government of Somalia 2019). Importantly, in order to remain neutral, independent and impartial humanitarian agencies in Somalia are reluctant to use a database or registry owned and operated by the government, which is party to the ongoing conflicts. Therefore, a three-stage approach consisting of shortterm, mid-term and long-term objectives could be adopted to establish an integrated data system for CTP in Somalia. This approach is presented in the next section.

\section{Basic integrated beneficiary registry in the short-term}

In the short term, a basic integrated beneficiary registry co-owned by donors and humanitarian agencies can be developed. This registry is basic in the sense that it will host only the minimum data variables that humanitarian agencies are willing to share. Accordingly, humanitarian agencies will still operate their own databases, but use the registry as a third-party exchange layer through which they can share a specific set of data variables for coordination, deduplication and planning purposes. This will require a software application that links the registry dynamically to the MIS of various humanitarian agencies and systematically transforms data into information.

An effective governance structure has to be established to oversee the development and management of the registry. The governance arrangement must have agile accountability and oversight structures to ensure effectiveness. At minimum, a technical committee or equivalent should be established with a primary mandate of providing technical leadership. Moreover, a multistakeholder steering committee or management board should be created to provide overall oversight and strategic direction on the development, management and use of the registry. Given the vested interests in controlling the access to and using registration data, the registry should be managed/hosted by a neutral entity with adequate technical capacity to ensure fair access to data. While a neutral agency can coordinate the use of the registry and run its secretariat, hosting of the registry could be undertaken by a private company, which is a common practice. For instance, in Brazil development of policy and data collection instruments are done at government ministry level while Caixa (a bank) manages the registry, Cadastro Unico. Working with the private sector can enhance efficiency, promote innovation and ensure access to special skills and technologies that humanitarian agencies lack. However, private firms are also considered by some donors and humanitarian agencies as a source of profiteering or exploitation that undermine the humanitarian mission. Furthermore, a private sector firm, just like humanitarian agencies, may fail to protect recipients' personal data adequately, leading to data privacy and protection breaches. An alternative to a private firm is establishing an independent corporation co-owned by donors and humanitarian agencies to manage and/or host the registry. This proposal, however, could be resource-intensive, since initial investments must be made to establish the corporation, including acquiring equipment and staff. It is worth noting that every option considered to host and manage the registry comes with opportunities and risks. Thus, tradeoffs must be made to select a viable option.

An important step in establishing the registry will be to coordinate the harmonisation initiatives being implemented by various consortia such as the Somalia Cash Consortium, as well as the government and the World Bank who are planning to develop a unified registry. The incentive for coordinating with the consortia includes opportunities for discussing and agreeing on the data variables that should be shared due to their relevance for CTP and building on the gains that have already been realised, such as the registration forms that have been harmonised in various consortia. Effective coordination can create synergies, prevent duplication of efforts in harmonising data systems and ensure that ongoing harmonisation initiatives contribute to the development of a long-term government-led solution.

While biometrics and a foundational ID system would provide the most appropriate identification mechanisms to operationalise the registry, developing these in the short term poses a significant challenge due to political, financial and technical constraints as explained earlier. As the experience of Brazil illustrates, an algorithm based on matching a combination of variables, such as name, mother's name, location and phone number, to determine potential duplication could be considered as a short-term solution. While these algorithms are not always $100 \%$ accurate, they could provide a short-term fix to identification challenge in Somalia (Barca 2017).

Establishing the registry will also require a data sharing agreement to be put in place. This calls for a review of data privacy and protection risks that have to be addressed. Based on this review, humanitarian agencies should (1) define the data variables that can be shared and the protocol for sharing them; (2) define and agree on the rules for ensuring data security and privacy and how conflicts will be addressed when sharing and using data; and (3) agree on a framework for monitoring and evaluating data use and management practices to ensure compliance with data privacy and protection rules. Furthermore, the data sharing agreement should clearly specify the roles, responsibilities and rights of stakeholders with respect to ownership, sharing, using and protecting the data. It is worth noting that formal agreements are 
not always adequate and can be difficult to reach (Barca 2017). This calls for establishing a mechanism for regular consultations and negotiations geared towards demonstrating to stakeholders the importance of sharing data.

\section{Expanded integrated beneficiary registry in the medium term}

In the medium term, the integrated beneficiary registry can be expanded as humanitarian agencies agree to share more data variables. Furthermore, a more reliable ID system that incorporates biometric technology can be adopted. As discussed earlier, this will require investing in adequate data protection, standardisation of biometric data, and the software and hardware required to establish the system. Although the ownership of the registry can remain with donors and humanitarian agencies in the medium term, it will be important for donors and UN agencies to make deliberate efforts to build the capacity of the government to operate an integrated beneficiary registry and to implement social protection programmes in the long term. This should include support to establish effective institutional and legal frameworks to host and manage the registry in a government institution.

Moreover, donors and UN agencies such as United Nations Children's Fund should work with the government to establish an effective birth registration system in the medium term. Somalia has a fragmented civil registration and vital statistics system, with paper-based birth and death certificates being issued by mayors of various cities without coordination across regions. The birth registration rate in Somalia-estimated at 3\%-is one of the lowest in the world (World Bank 2016). Birth registration is important since it leads to issuance of a birth certificate that serves as a breeder document that facilitates the acquisition of identification documents such as national ID cards and passports (Peters 2016). As the experiences of Uganda, Senegal and Pakistan demonstrate, the fairly well-developed mobile phone infrastructure in Somalia can be leveraged to establish an efficient and cost-effective digital birth registration system (GSMA 2013).

\section{Transition to a government-led registry in the long-term}

In the long term, the integrated beneficiary registry should be handed over to the government upon establishment of adequate capacity and its coverage should be expanded to support implementation of government-led social protection programmes. Additionally, the government-led digital ID project should be completed and rolled out. The digital ID can be linked to the integrated beneficiary registry and used with biometric data to ensure reliable identification and verification. The ID's MIS can provide an application programming interface that allows providers of cash assistance to retrieve the identification records or details of recipients upon providing an ID number for verification (World Bank n.d.). This can facilitate an audit trail down to the recipients of cash transfers, thereby enhancing transparency and accountability.

As Somalia transitions to government-led and povertytargeted social assistance schemes, a social registry could be created to serve as a targeting database, depending on the long-term policy direction of the country. Building on the digital birth registration system, the government with support from donors and UN agencies should establish a reliable civil registration and vital statistics system that records key events such as deaths, marriage, divorce and adoption. Recording these events can help to reduce fraud in humanitarian CTP or government social protection programmes. For instance, linking an integrated beneficiary registry to the civil registration and vital statistics system can help to identify registered persons who have died, thereby preventing the transfer of cash assistance to 'ghost' recipients. Importantly, statistics from a civil registration and vital statistics system will provide the basis for effective planning and provision of government services, including health, education and social protection programmes, to reduce vulnerability and reliance on humanitarian aid.

\section{Using blockchain technology to establish an integrated data system}

An important area that relates to integrating data systems and sharing data, but that requires further research, is the use of blockchain technology. Blockchain is a type of distributed database hosted across a network of multiple participants and can be used to share information and to transfer digital assets in a fast, traceable and safe way (Ko and Verity n.d.). Blockchain facilitates sharing of data among multiple agencies by providing an information marketplace that can be accessed by all users. Moreover, digital signatures are used to ensure the privacy of users. Therefore, in CTP a shared platform based on blockchain can be established to enable humanitarian agencies to share programme and beneficiary data easily and responsibly.

In emergency contexts where populations lack valid national IDs as is the case in Somalia, blockchain can be used to provide accessible and verifiable digital identification. For instance, in Jordan, the World Food Programme has used a blockchain based system (Building Blocks) to provide aid to 10,000 Syrian refugees. The system provides digital identities that refugees use to purchase items using biometrics (International Center for Humanitarian Affairs 2018).

Blockchain can also support establishment of digital cash payment systems that are traceable, low cost, secure 
and interoperable with the potential to track funds from the donor to the final recipients (Ko and Verity n.d). This provides an audit trail to ensure transparency. For instance, the International Federation of Red Cross and Red Crescent (IFRC) and the Kenya Red Cross Society (KRCS) implemented a pilot cash transfer programme using blockchain in Isiolo County, Kenya in 2018 to ensure timely delivery of aid while enhancing transparency and accountability to donors and aid recipients.

While blockchain has the potential to address the data challenges facing CTP, humanitarian agencies should be aware of the challenges that are likely to limit its application in Somalia. As a relatively new and intricate technology, practitioners in the CTP space find blockchain to be difficult to understand. This calls for development of more user-friendly blockchain solutions. In addition, most of the humanitarian cash transfer programmes that are supported by blockchain are still at pilot stage. Accordingly, the actual impacts of blockchain-based solutions are not clearly understood to catalyze their uptake.

Adopting a blockchain-based data sharing platform in Somalia will also depend in part on the extent to which such a system will be compatible with existing databases or data management platforms, which humanitarian agencies have invested significant resources to build. Using blockchain also requires reliable access to the Internet which can be a significant challenge in Somalia, especially in rural areas. In the IFRC and KRCS pilot, for instance, a data collection tool that works offline had to be used due to limited availability of Internet connection (International Federation of Red Cross and Red Crescent 2018).

There are also social, ethical and legal issues that may slow adoption of blockchain. In particular, obtaining legitimate, informed and adequate consent remains a challenge in systems that use complex data structures such as blockchain. Moreover, blockchain uses an immutable ledger which can undermine efforts to comply with legislation/regulations that require data to be purged permanently from a database or changed upon request by the recipients of cash aid (Zwitter and Boisse-Despiaux 2018). Furthermore, digital identities, mobile phones or bank accounts used in blockchain enabled CTP may be used for surveillance over recipients of cash assistance by corporations, donors and government authorities (Korkmaz 2018). Without adequate support and permission from the government, adoption of a digital identity system with citizens' data hosted outside a government database may not be possible in Somalia. These issues should be considered carefully and explored through further research to inform any future decisions to use blockchain to address the data challenges in humanitarian CTP in Somalia.

\section{Conclusion}

Harmonising data systems presents both long-term opportunities and short-term risks. On the one hand, an integrated data system holds the key to improving the effectiveness of CTP in Somalia by providing a mechanism for preventing overlaps and duplication of assistance, enhancing coordination and caseload planning, ensuring cost savings/efficiency and promoting transparency and accountability by enabling the sharing, analysis and comparison of programme data across humanitarian agencies. On the other hand, harmonising data systems comes with increased legal, fiduciary, reputational and data privacy and protection risks, as well as potential disruption of power dynamics in the humanitarian space and costs associated with restructuring operations. These risks affect the extent to which humanitarian agencies are willing to harmonise data systems. Nonetheless, the ongoing initiatives to harmonise data systems provide important opportunities for developing a robust integrated data system for CTP.

While efforts to improve harmonisation have moved forward, the CTP data system in Somalia is still fragmented. This is attributed in part to technical, political and legal constraints. Although the government has the political will to establish an integrated data system for social protection programmes, it lacks the technical and financial capacity to do so. Competition between humanitarian agencies and the lack of adequate cooperation among donors continue to slow efforts to harmonise data systems. This calls for better political, administrative and technical collaboration among donors and humanitarian agencies to harmonise data systems in order to improve the efficiency and effectiveness of their cash transfer programmes. While a short-term solution will be needed, all actors must start working collaboratively towards a government-led solution with donor support in the medium to long terms to facilitate a transition from reliance on short-term fragmented humanitarian cash transfers to more reliable social protection programmes provided by the government. Accordingly, current harmonisation efforts should culminate in the establishment of an integrated beneficiary registry and a social registry to support a vibrant government-led social protection sector in the long term.

\section{Abbreviations}

CTP: Cash transfer programming; ICRC: International Committee of the Red Cross; ID: Identification; IDP: Internally displaced persons; IPC: Integrated Food Security Phase Classification; MIS: Management information system; UN: United Nations; UNHCR: United Nations High Commissioner for Refugees; VRC: Village relief committee

\section{Acknowledgements}

The author acknowledges the support from Richard Chirchir, Nisar Majid, Bill Anderson and Martha Bekele who provided useful insights and guidance to this study, as well as Eastone Owino who provided significant support 
during data collection and Mariam Ibrahim who managed this research project.

\section{Author's contributions}

BO carried out data collection, analysis and writing of the research report. The author read and approved the final manuscript.

\section{Author's information}

Not applicable.

\section{Funding}

This work was supported by the United Kingdom's Department for International Development through the East Africa Research Fund.

\section{Availability of data and materials}

The datasets used for this study are available from the corresponding author on reasonable request.

\section{Competing interest}

The author declares that he has no competing interests.

\section{Received: 28 October 2019 Accepted: 8 July 2020}

Published online: 28 July 2020

\section{References}

Barca V (2017) Integrating data and information management for social protection: Social registries and integrated beneficiary registries. Department of Foreign Affairs and Trade. Australia, Canberra

Barrett S, Kidd S (2015) The design and management of cash transfer programmes: an overview. KfW Development Bank, Frankfurt

Carmona M (2018) Is biometric technology in social protection programmes illegal or arbitrary? An analysis of privacy and data protection. Social Protection Department, International Labour Office, Geneva

Chirchir R (2017) No identity crisis for social protection programmes that link with ID agencies. Development Pathways https://www. developmentpathways.co.uk/blog/no-identity-crisis-for-social-protectionprogrammes-that-link-with-id-agencies/.

Chirchir R, Farooq S (2016) Single registries and social registries: clarifying the terminological confusion. Development Pathways https://www. developmentpathways.co.uk/wp-content/uploads/2016/11/Single-and-SocialRegistries-1.pdf. Accessed 17 May 2019

Clark D (2017) Biometrics in digital financial services: an overview. Financial Sector Deepening Africa, Nairobi

Corps M (2017) The cash transfer implementation guide: part of the cash transfer programming toolkit. Mercy Corps, Portland

Cross T, Johnston A (2011) Cash transfer programming in urban emergencies: a toolkit for practitioners. Cash Learning Partnership, Oxford

Daniels C, Anderson G (2018) Evaluation of the 2017 Somalia humanitarian cashbased response. Inter-Agency Cash Working Group, Mogadishu

Department for International Development (2014) How to note: assessing the strength of evidence. Department for International Development, London

European Commission (2019a) EU cash compendium 2019: Doing more cash better. European Commission, Brussels

European Commission (2019b) EU data protection rules. https://ec.europa.eu/ commission/priorities/justice-and-fundamental-rights/data-protection/2018reform-eu-data-protection-rules_en.

European Commission (2019c) Case study Mali: guidance package on social protection across the humanitarian-development nexus. https://europa.eu/ capacity4dev/sp-nexus/documents/span-2019-case-study-mali.

Federal Government of Somalia (2019) Somalia Social Protection Policy. Federal Government of Somalia, Ministry of Labour and Social Affairs, Mogadishu

Forti D (2011) A pocket of stability: Understanding Somaliland. ACCORD https:// www.files.ethz.ch/isn/137755/op_2011_2.pdf. Accessed 22 June 2019

Gellman R (2013) Privacy and biometric ID systems: an approach using fair information practices for developing countries. Centre for Global Development, Washington, DC

Goodman C, Majid N (2017) In pursuit of a safety net programme in the short term paving the way to a social protection approach in the long term: issues and options. https://www.dai.com/uploads/ASiST\%20Report_Somalia_Finalreport.pdf. Accessed 29 May 2019
Grellety E, et al. (2017) Effects of unconditional cash transfers on the outcome of treatment for severe acute malnutrition (SAM): a cluster-randomised trial in the Democratic Republic of the Congo BMC Medicine 15;1-19

GSMA (2013) Mobile birth registration in Sub-Saharan Africa: a case study of Orange Senegal and Uganda Telcom solutions. GSMA https://www.gsma. com/identity/wp-content/uploads/2013/05/Mobile-Birth-Registration-in-SubSaharan-Africa.pdf. Accessed 25 May 2019

Hagen-Zanker J, Mallett R (2013) How to do a rigorous, evidence-focused literature review in international development: a guide note. Overseas Development Institute https://www.odi.org/sites/odi.org.uk/files/odi-assets/ publications-opinion-files/8572.pdf.

Hammond L, Vaughan-Lee H (2012) Humanitarian space in Somalia: a scarce commodity. Humanitarian Policy Group, Overseas Development Institute, London

Hedlund K, Majid N, Maxwell D, Nicholson N (2013) Final evaluation of the unconditional cash and voucher response to the 2011-12 crisis in southern and central Somalia. UNICEF https://www.unicef.org/evaldatabase/files/ Somalia_2013-002_Humanitarian_Outcomes_Somalia_Cash_and_Voucher_ Evaluation_Full_Report.pdf.

Initiatives D (2019) Global Humanitarian Report 2018. Development Initiatives, Bristol

International Centre for Humanitarian Affairs (2018) Blockchain technology in humanitarian programming: a pilot project in cash transfer programming in Kenya. International Centre for Humanitarian Affairs https://cash-hub.org/-/ media/cashhub-documents/resources/2018/blockchain-technology_pilotproject-in-kenya_2018.pdf.

International Committee of the Red Cross (2007) Guidelines for cash transfer programming. International Red Cross and Red Crescent Movement, Geneva

International Federation of Red Cross and Red Crescent (2018) Blockchain open loop cash transfer pilot project. International Federation of Red Cross and Red Crescent https:/www.alnap.org/system/files/content/resource/files/ main/1557828622.Blockchain\%20pilot\%20study\%20KRCS\%20\%26\%20IFRCKenya\%200ct\%202018.pdf.

International Organization for Standardization (2017) ISO/IEC 19794-1:2011 information technology - Biometric data interchange formats. https://www. iso.org $/ \mathrm{standard} / 50862$.html? browse $=$ tc.

Ko $V$ Verity, $A$ (n.d) Blockchain for the humanitarian sector: future opportunities. UN-OCHA https://reliefweb.int/sites/reliefweb.int/files/resources/ BlockChain\%20for\%20the\%20Humanitarian\%20Sector\%20-\%20Future\%2 0Opportunities\%20-\%20November\%202016.pdf.

Korkmaz E (2018) Blockchain for refugees: great hopes, deep concerns. University of Oxford https://www.qeh.ox.ac.uk/blog/blockchain-refugees-great-hopesdeep-concerns.

Leite P, Karippacheril T, Sun C, Jones T, Lindert K (2017) Social registries for social assistance and beyond: a guidance note and assessment tool. World Bank Group, Washington, DC

Longley C, Dunn S, Brewin M (2012) Cash and Voucher Monitoring Group final monitoring report of the Somalia cash and voucher transfer programme. Overseas Development Institute https://www.odi.org/sites/odi.org.uk/files/ odi-assets/publications-opinion-files/8521.pdf.

Mackey K, Gol P (2018) Community based targeting guidelines for Somalia. Somalia Food Security Cluster, Mogadishu

Majid N, Abdirahman K, Hassan S (2017) Remittances and vulnerability in Somalia: assessing sources, uses and delivery mechanisms. Rift Valley Institute, London

Majid N, Harmer A (2016) Collective resolution to enhance accountability and transparency in emergencies: Southern Somalia report. Transparency International, Berlin

Majid N, Menkhaues K (2019) Somalia Stability Fund: access and inclusion. Somalia Stability Fund, London

Maxwell D, Majid N, Adan G, Abdirahman K, Kim J (2015) Facing famine: Somalia experiences in the famine of 2011. Tufts University, Somerville, Feinstein International Center

Mosley J (2015) Somalia's federal future: layered agendas, risks and opportunities. The Royal Institute of International Affairs. Chatham House, London

O'Brien C, Congrave J, Sharp K, Keita N (2018) Shock-responsive social protection systems research: case study - social protection and humanitarian responses to food insecurity and poverty in Mali. Oxford Policy Management, Oxford

Peters B (2016) Civil registration and vital statistics as a tool to improve public management. Inter-America Development Bank https://publications.iadb.org/ publications/english/document/Civil-Registration-and-Vital-Statistics-as-a-Toolto-Improve-Public-Management.pdf. 
UNHCR et al (2015) Operational guidance and toolkit for multipurpose cash grants. Cash Learning Partnership, Oxford

United Nations Development Group (2017) Data privacy, ethics and protection guidance note on big data for achievement of the 2030 Agenda. United Nations Development Group, New York

United Nations Office of Counter-Terrorism (2018) United Nations compendium of recommended practices for the responsible use and sharing of biometrics in counter-terrorism. United Nations Biometrics Institute https:/www.un.org/ sc/ctc/wp-content/uploads/2018/06/Compendium-biometrics-final-versionLATEST_18_JUNE_2018_optimized.pdf.

United Nations Security Council (2012) Report of the monitoring group on Somalia and Eritrea pursuant to Security Council resolution:2002(2011) https:/www.un.org/ga/search/view_doc.asp?symbol=S/2012/544\&referer= http://www.\%20un.org/sc/committees/751/mongroup.shtml\&Lang=E.

World Bank (2016) Toward a Somalia identification system: ID4D diagnostic International Bank for Reconstruction and. Development/The World Bank, Washington, DC

World Bank (2017) Social protection enhancement project. World Bank http:// documents.worldbank.org/curated/en/960451493154941751/pdf/TM00194P160674-04-25-2017-1493154939473.pdf.

World Bank (2018a) Technology landscape for digital identification. International Bank for Reconstruction and. Development/The World Bank, Washington, DC

World Bank (2018b) G20 digital identity onboarding. World Bank Group, Washington, DC

World Bank (n.d.) Integrating social registry with ID systems. World Bank https:// olc.worldbank.org/sites/default/files/3.pdf. Accessed 7 June 2019

World Food Programme (2018) Somalia databases and beneficiary registries for cash transfer programming. World Food Programme Somalia, Nairobi

Zwitter A, Boisse-Despiaux M (2018) Blockchain for humanitarian action and development aid. Journal of International Humanitarian Action 3:1-7. https:// doi.org/10.1186/s41018-018-0044-5

\section{Publisher's Note}

Springer Nature remains neutral with regard to jurisdictional claims in published maps and institutional affiliations.

\section{Submit your manuscript to a SpringerOpen ${ }^{\circ}$ journal and benefit from:}

- Convenient online submission

- Rigorous peer review

- Open access: articles freely available online

- High visibility within the field

- Retaining the copyright to your article

Submit your next manuscript at $\boldsymbol{\nabla}$ springeropen.com 